\title{
Capillary density has no value as an early biomarker of bevacizumab efficacy in metastatic colorectal cancers: a prospective clinical trial
}

\author{
Jean-David Fumet ${ }^{1, *}$, Aurélie Bertaut ${ }^{2,3}$, Leila Bengrine ${ }^{1}$, Patricia Lapierre ${ }^{3}$, Julie \\ Vincent ${ }^{1}$, François Ghiringhelli ${ }^{1,2,3, *}$ and Nicolas Falvo ${ }^{4}$ \\ ${ }^{1}$ Department of Medical Oncology, Centre Georges-François Leclerc, Dijon, France \\ ${ }^{2}$ Department of Epidemiology and Biostatistics, Georges François Leclerc Center, Dijon, France \\ ${ }^{3}$ Center of Clinical Research, Georges François Leclerc Center, Dijon, France \\ ${ }^{4}$ Department of Radiology, François-Mitterrand Teaching Hospital, Dijon, France \\ *These authors have contributed equally to this work
}

Correspondence to: Jean-David Fumet, email: jdfumet@cgfl.fr

Keywords: angiogenesis; bevacizumab; capillary rarefaction; colorectal cancer

Received: October 20, $2017 \quad$ Accepted: November 10, $2017 \quad$ Published: December 01, 2017

Copyright: Fumet et al. This is an open-access article distributed under the terms of the Creative Commons Attribution License 3.0 (CC BY 3.0 ), which permits unrestricted use, distribution, and reproduction in any medium, provided the original author and source are credited.

\section{ABSTRACT}

Background: Bevacizumab is a recombinant humanized monoclonal immunoglobulin G1 antibody targeting VEGF-A. It is currently used with chemotherapy as the first- or second-line therapy in metastatic colorectal cancer. Previous studies have showed that anti-angiogenic agents decrease capillary density. We evaluated the link between decreased capillary density and the response to bevacizumab-based chemotherapy.

Results: Overall, $\mathbf{4 3}$ patients with metastatic colorectal cancer treated with firstline bevacizumab-based chemotherapy were enrolled. At Day 90, progressive disease was observed in 12 patients $(27.9 \%)$. All patients presented decreased capillary density. ROC analysis at different time points and capillary density variation showed a poor diagnostic performance regarding response at Day 90.

Materials and Methods: From 2013 to 2015, patients with metastatic colorectal cancer treated in our French cancer care center and eligible for bevacizumab with chemotherapy were enrolled in a prospective single-center study. Capillary density was assessed using capillaroscopy at Day 1, Day 15 and Day 30. Response to bevacizumab was assessed at Day90 according to CHUN criteria.

Conclusions: Capillary density measured using capillaroscopy is not a good predictor of the early response to bevacizumab-based chemotherapy. (NCT01810744).

\section{INTRODUCTION}

Colorectal cancer $(\mathrm{CRC})$ is the third most common cancer worldwide [1]. Approximately $25 \%$ of patients present with metastases at the initial diagnosis and almost $50 \%$ of patients with CRC will develop metastases [2]. Fluorouracil-based palliative chemotherapy has been the mainstay treatment for many years. The availability of the cytostatic drugs irinotecan and oxaliplatin has improved the prognosis of metastatic CRC (mCRC) patients. In the last decade, a new class of « anti-angiogenic » target therapies have been included in treatments for colorectal cancer and several other cancers (Breast cancer, renal clear cell carcinoma, ovarian cancer or non-small cell lung cancer) [3-8]. Neoangiogenesis results from an imbalance between pro-angiogenic factors like VEGFs (Vascular Endothelial Growth Factor) and anti-angiogenic factors. This mechanism is known to be required for tumor growth and the development of metastasis. VEGF-A, a diffusible glycoprotein produced by normal and neoplastic cells, is one of the most important regulators of physiological and pathological angiogenesis [9]. VEGF-A-dependent angiogenesis, which contributes to tumor cell proliferation, is thus a target for cancer therapy.

Several anti-angiogenic target therapies are currently used in the treatment of human cancers. Bevacizumab is 
a recombinant humanized monoclonal immunoglobulin G1 antibody targeting VEGF-A. It has been approved for the treatment of advanced colorectal, breast, lung, renal, and ovarian carcinomas [4-8, 10]. Adding bevacizumab to currently used chemotherapy improves outcomes in patients with mCRC. Indeed, Bevacizumab, when used in the first- and second-line treatment of mCRC, improved progression-free survival (PFS) and overall survival (OS) $[7,8,11,12]$. In recent clinical trials, the median OS of patients with mCRC treated with chemotherapy alone was around 13 to 20 months but the median OS of patients with $\mathrm{mCRC}$ treated with bevacizumab combined with chemotherapy was more than 25 months $[7,8,13]$. However, to date no predictive or early biomarker of efficacy has been validated.

One of the most frequent side effects of treatment with bevacizumab is hypertension (HT). The perfusion of exogenous VEGF-A is accompanied by hypotension through the activation of endothelial NO-synthase and the production of nitric oxide $[14,15]$. It was therefore suggested that the pathophysiology of hypertension induced by bevacizumab or other antiangiogenic agents may be due to neutralization of the major physiological effects of VEGF-A on endothelial cells and therefore on the vascular wall. This hypothesis implies that the inhibition of endothelial NO synthase in response to various stimuli may alter the endothelial vasculature and increase sympathetic adrenergic activity [14]. Together, such biological events should lead to capillary rarefaction. Capillaries are the smallest blood vessels in the human body with a function in the exhange of materials between blood and tissue. Capillary density is defnied as the count of perfused capillary per $\mathrm{mm} 2$. It has been used as an indicator of the quality of issue perfusion.

Capillaroscopy is a non-invasive, easy and safe diagnostic technique designed to evaluate small vessels of the microcirculation in the nailfold and thus evaluate capillary density. In the nailfold, terminal rows of capillaries run parallel to the skin surface and, therefore, all morphological details and the nature of the blood flow can be examined. Capillaroscopy allows the precise qualitative and quantitative evaluation of the microcirculation and is a valuable tool in the daily practice of rheumatologists [16].

To our knowledge, only two studies with 14 and 16 patients, respectively, have described a decrease in capillary density during treatment with anti-angiogenic therapy and observed a correlation between capillary density reduction and bevacizumab efficacy in various types of cancer $[17,18]$. However, this observation has not been reproduced prospectively in a larger and more homogenous cohort of patients in the setting of a clinical trial.

We therefore investigated variations in capillary density in patients with mCRC treated with bevacizumabbased therapy and determined their relationship with the response to treatment, PFS and OS.

\section{RESULTS}

\section{Patients' characteristics}

Forty-three patients with metastatic colon cancer were enrolled. The main demographic and clinical characteristics of the patients are listed in Table 1. Overall, $47.6 \%$ of patients had right-side colon cancer, $28.6 \%$ of patients had left-side colon cancer and $23.8 \%$ of patients had rectal cancer. Of these patients, $11(25.6 \%)$ had Wild Type (WT) K-RAS status, 21 (48.9\%) had K-RAS exon 2 mutated status and four (9.3\%) had BRAF-mutated status. Seven $(16.2 \%)$ patients had unknown status. Around half of the patients had surgery for their primary tumor, with R0 resection for the vast majority $(93 \%)$. All included patients were in the first-line of metastatic treatment. All patients except one received bi- or tri-chemotherapy (Table 1).

\section{Survival and response rates}

The median follow-up was 11.7 months (0.9515.47). Overall, after 1 year of follow-up, 30 patients $(69.7 \%)$ had progressive disease and 12 patients $(27.9 \%)$ had died. Median PFS was 7.6 months (95\% CI: $5.2-$ 11]. PFS at 6 months was $65 \%$ (95\% CI: [48.5\%-77\%]) while PFS at one year was $12 \%$ (95\% CI: [2.5\%-30\%]) (Figure 1A).

OS at 6 and 12 months was 83\% (95\% CI: [68\%$91.5 \%])$ and $66 \%$ (95\% CI: [47.5\%-80\%]), respectively (Figure 1B).

Three months after the initiation of therapy, 10 patients had progressive disease and two had died.

\section{Vascular assessment}

Capillary density was measured in 37 patients during treatment with bevacizumab. For the six remaining patients, no valid capillaroscopy assessments of capillary density could be obtained because of technical problems. During the treatment with bevacizumab, capillary density had significantly decreased on days 15 and 30 . The median capillary count was 8.19 [6.00-11.00] before therapy and 4.25 [1.75-9.13] and 3.50 [1.00-8.00] after 2 weeks and 4 weeks of therapy, respectively (Table 2). All of the patients except one showed a decrease in the capillary count at day 15 and all patients at day 30 (Figure 2A-2B).

Mean arterial blood pressure $(\mathrm{MAP}=(\mathrm{TAS}+2 \mathrm{TAD}) / 3)$ was measured in all patients. MAP was $95.33 \mathrm{mmHg}$ [81.66-132.33] before therapy and $99.33 \mathrm{mmHg}$ [73124.33] and 100.83 [79.66-127] after 2 weeks and 4 weeks of therapy, respectively (Table 2). MAP had increased in $50 \%$ and $51.2 \%$ of patients at day 15 and day 30 , respectively. We found no correlation between capillary density and MAP at any time point (Figure 3).

In both responders and non-responders, we found a decrease in capillary density at D15 and D30 after the 
Table 1: Baseline characteristics of the study population

\begin{tabular}{|c|c|c|c|}
\hline & & \multicolumn{2}{|l|}{ Total } \\
\hline & & $n=43$ & (\%) \\
\hline Age, years & $66.51[31.91-90.25]$ & & \\
\hline \multicolumn{4}{|l|}{ Sex } \\
\hline men & & 22 & 51,16 \\
\hline women & & 21 & 48,84 \\
\hline \multicolumn{4}{|l|}{ Primary disease site } \\
\hline right-sided colon & & 20 & 47,62 \\
\hline left-sided colon & & 12 & 28,57 \\
\hline Rectum & & 10 & 23,81 \\
\hline Missing & & 1 & \\
\hline \multicolumn{4}{|l|}{ KRAS } \\
\hline WT & & 11 & 28,95 \\
\hline mutated & & 27 & 71,05 \\
\hline Missing & & 7 & \\
\hline \multicolumn{4}{|l|}{ BRAF } \\
\hline WT & & 30 & 88,24 \\
\hline Mutated & & 4 & 11,76 \\
\hline Missing & & 9 & \\
\hline \multicolumn{4}{|l|}{ Surgery of primary site } \\
\hline no & & 21 & 48,84 \\
\hline yes & & 22 & 51,16 \\
\hline \multicolumn{4}{|l|}{ Quality of surgery } \\
\hline R0 & & 13 & 92,86 \\
\hline $\mathrm{R} 1$ & & 1 & 7,14 \\
\hline Missing & & 8 & \\
\hline \multicolumn{4}{|l|}{ pT $(n=22)$} \\
\hline 2 & & 1 & 5,26 \\
\hline 3 & & 8 & 42,11 \\
\hline 4 & & 9 & 47,37 \\
\hline 5 & & 1 & 5,26 \\
\hline Missing & & 3 & \\
\hline \multicolumn{4}{|l|}{$\mathrm{pN}(n=22)$} \\
\hline 0 & & 6 & 30 \\
\hline 1 & & 7 & 35 \\
\hline 2 & & 6 & 30 \\
\hline $\mathrm{X}$ & & 1 & 5 \\
\hline Missing & & 2 & \\
\hline \multicolumn{4}{|l|}{$\mathrm{pM}(n=22)$} \\
\hline 0 & & 11 & 55 \\
\hline 1 & & 9 & 45 \\
\hline Missing & & 2 & \\
\hline \multicolumn{4}{|l|}{ Adjuvant chemotherapy } \\
\hline no & & 32 & 74,42 \\
\hline yes & & 11 & 25,58 \\
\hline \multicolumn{4}{|l|}{ Chemotherapy regimen associated with bevacizumab } \\
\hline Oxaliplatine + Irinotecan + Fluoropymidine & & 7 & 16,28 \\
\hline Oxaliplatine + Fluoropymidine & & 28 & 65,12 \\
\hline
\end{tabular}


Fluoropymidine + Irinotecan

Fluoropymidine

Metastasis

Synchronous

Metachronous

Prior hypertension

no

yes
7

1

30

13

30

13

69,77

30,23

A

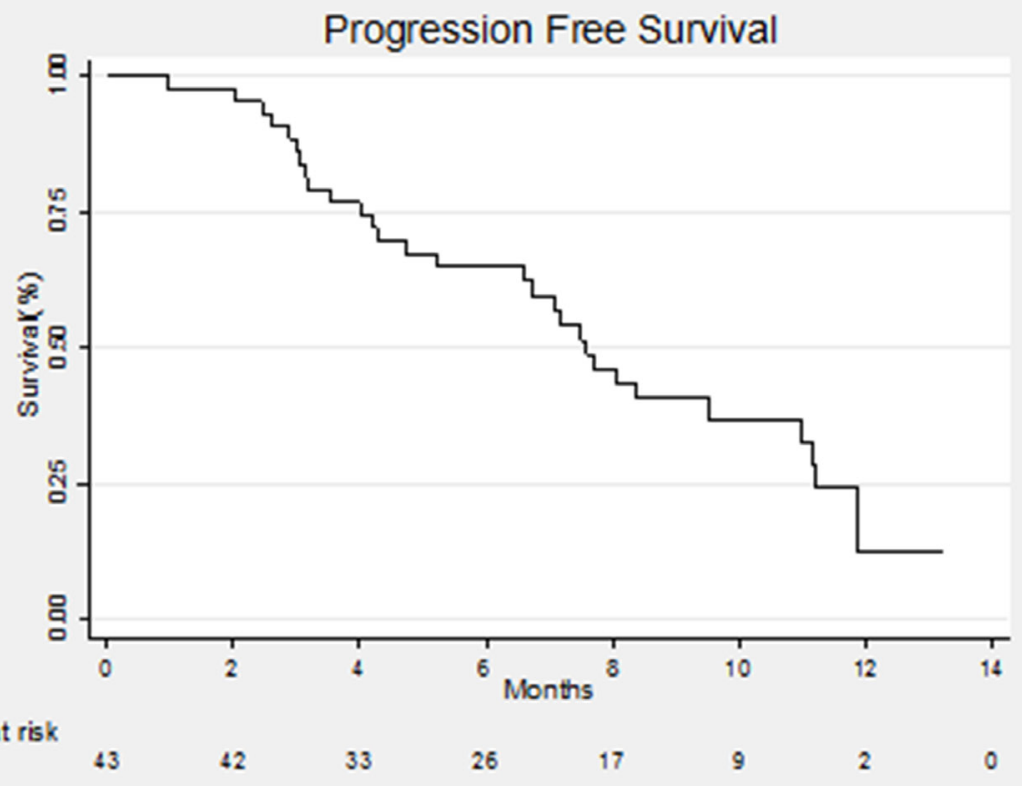

B

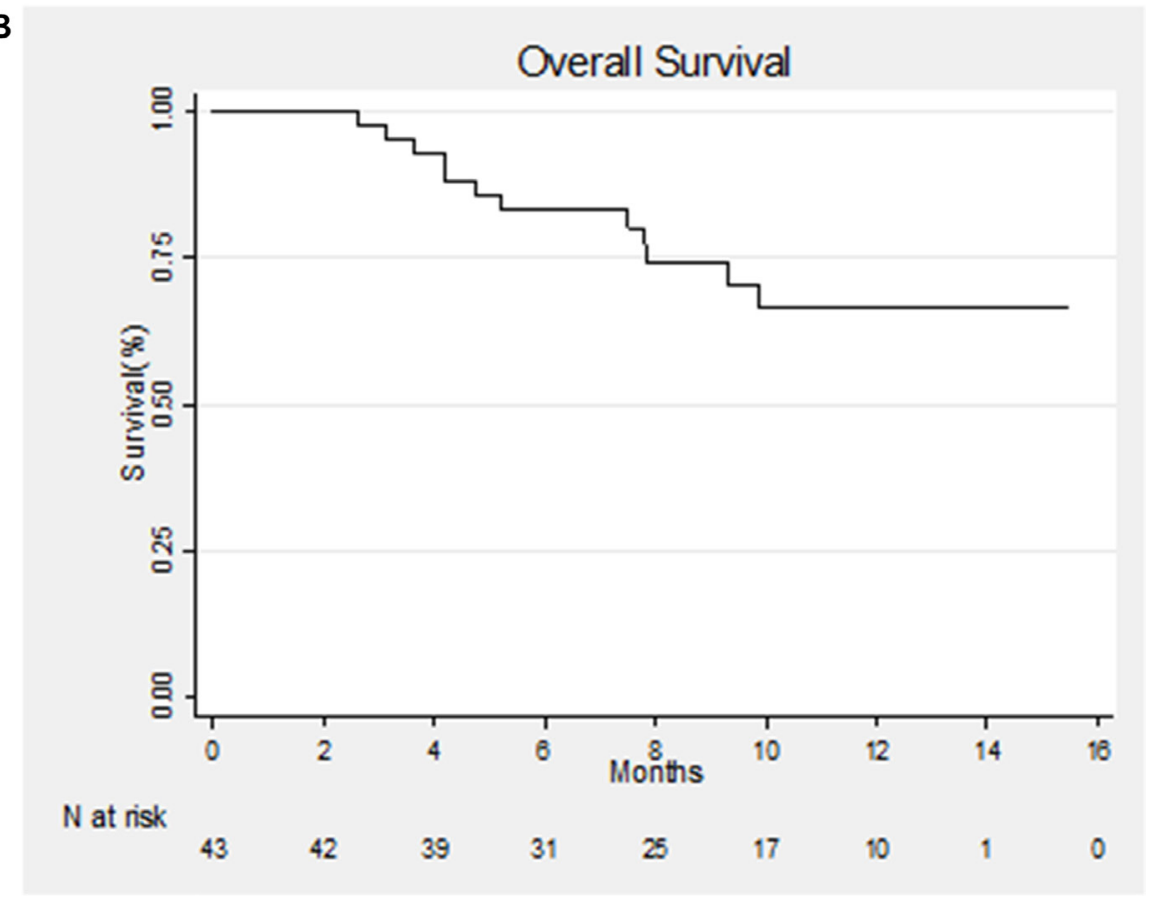

Figure 1: (A) Kaplan-Meier estimate of progression-free survival (PFS) for all patients. (B) Kaplan-Meier estimate of overall survival (OS) for all patients. 

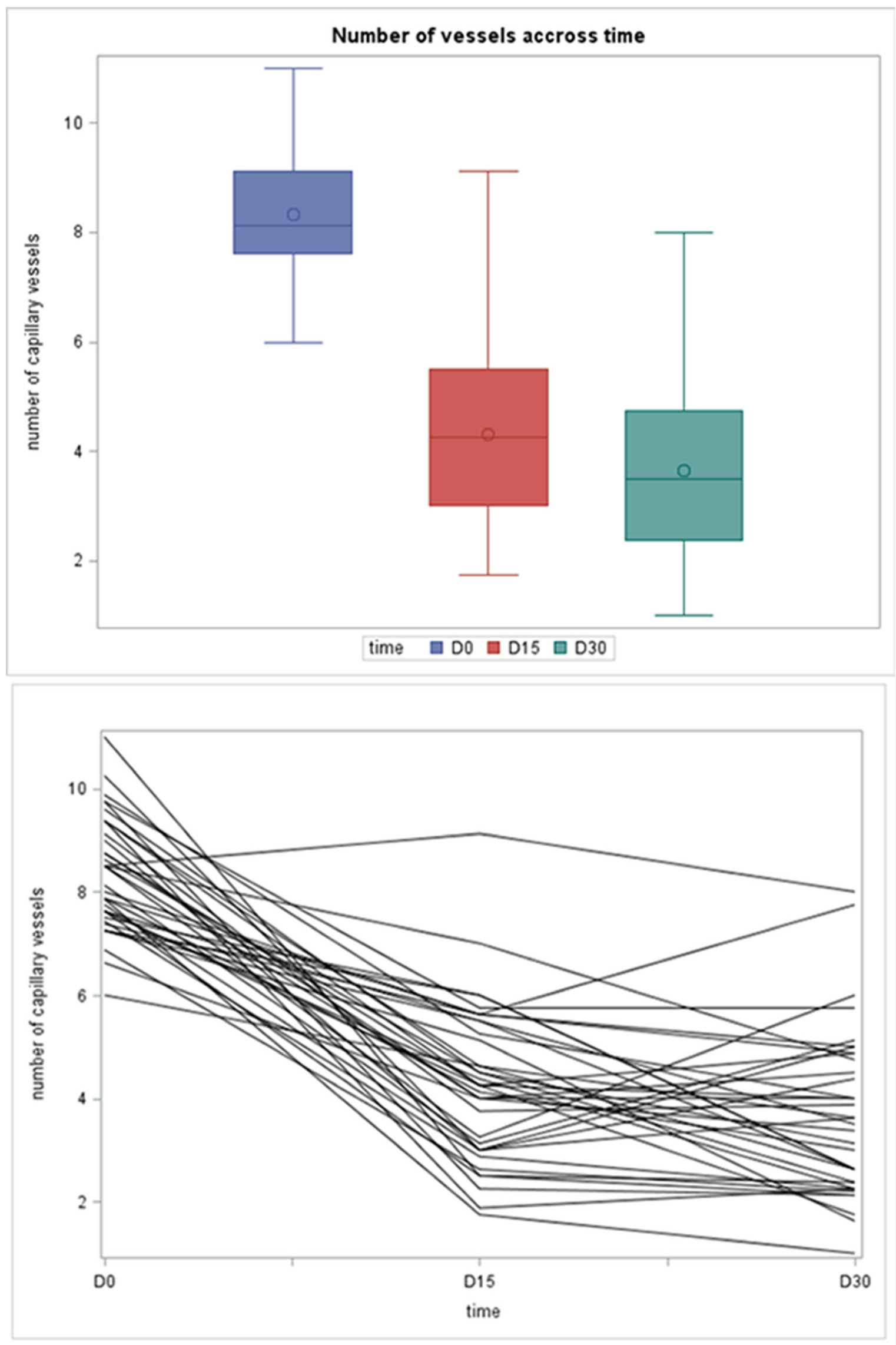

Figure 2: (A) Boxplot of capillary density at Day 0, Day 15 and Day 30. (B) Capillary density accross time. 
Table 2: MAP and capillary density at 3 time point (Day 0, Day 15 and D 30)

\begin{tabular}{lccc}
\hline & Day 0 & Day 15 & Day 30 \\
\hline MAP & & & 40 \\
$n$ & 36 & 43 & $101.1(11.3)$ \\
Mean (SD) & $97.6(11.1)$ & $98.5(10.8)$ & $100.8(79.7-127)$ \\
Median (min-max) & $95.3(81.7-132.3)$ & $99.3(73-124.3)$ & \\
Capillary density & & & 37 \\
$n$ & 37 & 37 & $3.65(1.61)$ \\
Mean (SD) & $8.33(1.10)$ & $4.30(1.53)$ & $3.50(1.00-8.00)$ \\
Median (min-max) & $8.13(6.00-11.00)$ & $4.25(1,75-9.13)$ & \\
\hline
\end{tabular}

initiation of therapy. There were no significant differences between these two groups in terms of capillary density at D1, D15 or D30 (Figure 4). Furthermore, no significant difference was found between the two groups for capillary density variation between D0 and D15, D0 and D30 and D15 and D30 (data not shown).

Regarding absolute capillary counts, the area under the ROC (Receiver Operating Characteristic) curve (AUCs) (Figure 5A) were $0.54(p=0.69 ; 95 \%$ CI $[0.3134-$ $0.7810]), 0.66(p=0.07 ; 95 \% \mathrm{CI}[0.4858-0.8324]$ and 0.58 $(p=0.47 ; 95 \% \mathrm{CI}[0.3673-0.7866])$, at D0, D15 and D30, respectively. (Figure 5A).

Concerning relative variations in capillary density between D0 and D15, D0 and D30, D15 and D30, the AUCs were $0.58(p=0.41 ; 95 \%$ CI $[0,38-0,78]), 0.52(p=$ $0.80 ; 95 \% \mathrm{CI}[0,31-0,75])$ and $0.55(p=0,67 ; 95 \% \mathrm{CI}$ $[0,32-0,77])$, respectively. (Figure 5B).

Similarly, none of these capillary density parameters could predict PFS or OS (data not shown).

\section{DISCUSSION}

Bevacizumab is one of the most frequently used target therapies associated with chemotherapy for metastatic colorectal cancer. To our knowledge, there are no biomarkers to predict its efficacy.

In this study, based on prospectively recorded data from a clinical trial and capillary density assessed using capillaroscopy, we found a decrease in capillary density in patients treated with bevacizumab. These findings are in agreement with previous studies. Indeed, Mourad et al. [17] showed that VEGF-A inhibition by bevacizumab caused a decrease in capillary density. Another study found the same results and demonstrated the reversibility of this phenomenon when bevacizumab therapy was stopped $[18,20]$. Interestingly, we observed a decrease in capillary density in all patients, thus demonstrating that bevacizumab had biological activity on normal nailfold microvasculature. Bevacizumab is used at $5 \mathrm{mg} / \mathrm{kg}$ every 2 weeks in colorectal cancer and at $10 \mathrm{mg} / \mathrm{kg}$ every 2 weeks in other diseases. It would be interesting to compare the effect of the two dosages on capillary density to determine whether increasing the dose increases the magnitude of the biological efficacy.

Previous publications reported that increased blood pressure during treatment with VEGF inhibitors has been associated with a longer time to tumor progression [21]. Surprisingly, we found no correlation between blood pressure and capillary density. Moreover, we found no association between a rapid increase in MAP and the response to therapy. We believe that these results show that increased MAP could not be considered a potential early biomarker of bevacizumab efficacy.

Very few studies have evaluated the correlation between variations in capillary density and survival. Capillaroscopy is a cheap, non-invasive method and capillary density could have been an interesting predictive marker of bevacizumab efficacy. Unfortunately, it would seem that capillary density is not useful to predict the efficacy of bevacizumab. Nailfold capillaries evaluated by capillaroscopy may not be a good surrogate of capillary density in the tumor. However, these negative results were also found in a study with a small number of patients, and the lack of any difference between responders and non-responders could be related to a lack of power.

It should nevertheless be noted that median PFS in our population was lower than that in phase 3 trials using bevacizumab in the first line $(7.6$ months in our cohort versus around 10 months in a recent trial) [7, 8]. Most recent studies demonstrated poorer survival in right-side compared with left-side colon cancer [24]. The high prevalence of right-side colon cancer in our population could explain this poor survival rate and may have affected our initial statistical hypothesis. Furthermore, our patients were not treated with the same bevacizumab-based chemotherapy. We could imagine that this heterogeneity may have altered the interpretation of our results.

In conclusion, in light of the findings of this prospective study, we can say that treatment with bevacizumab results in a rapid and persistent decrease in capillary density in all patients and that this decrease is not associated with a response to bevacizumab at Day 90 . 

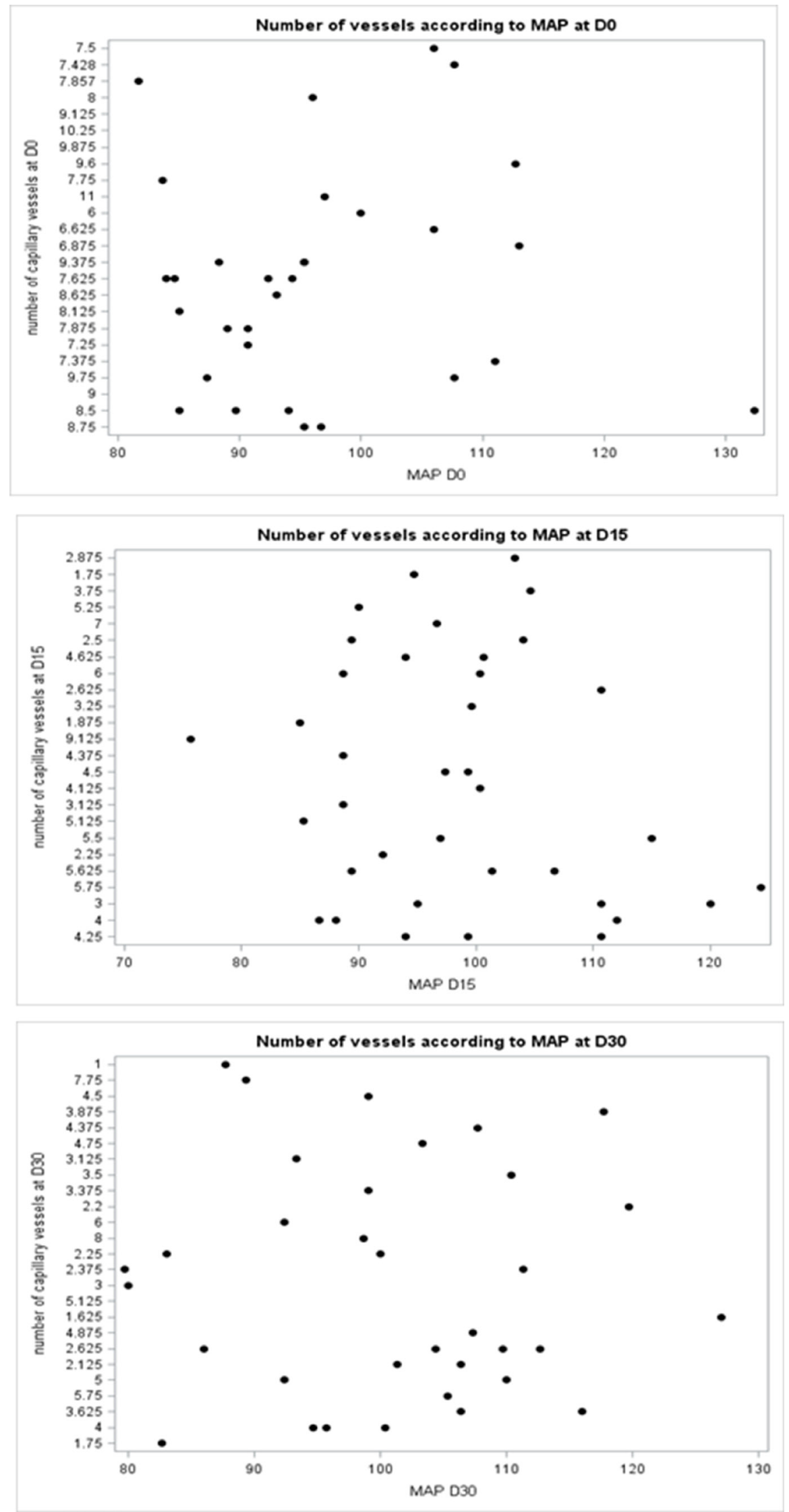

Figure 3: A scatter plot did not show correlation between capillary density and MAP at any time point (Day0, Day15 and Day30). 


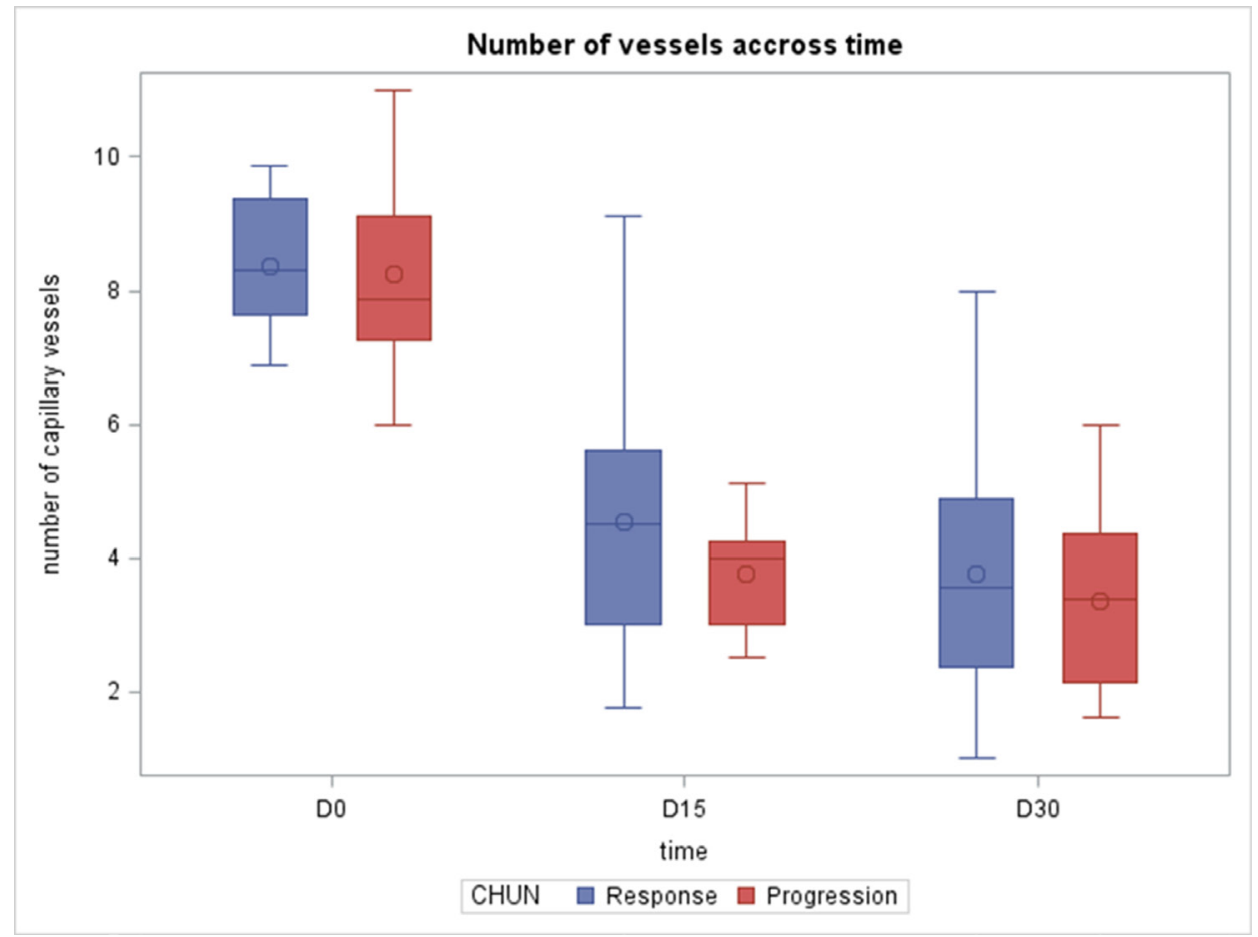

Figure 4: Capillary density at Day 0, Day 15 and Day 30 according to response to treatment.
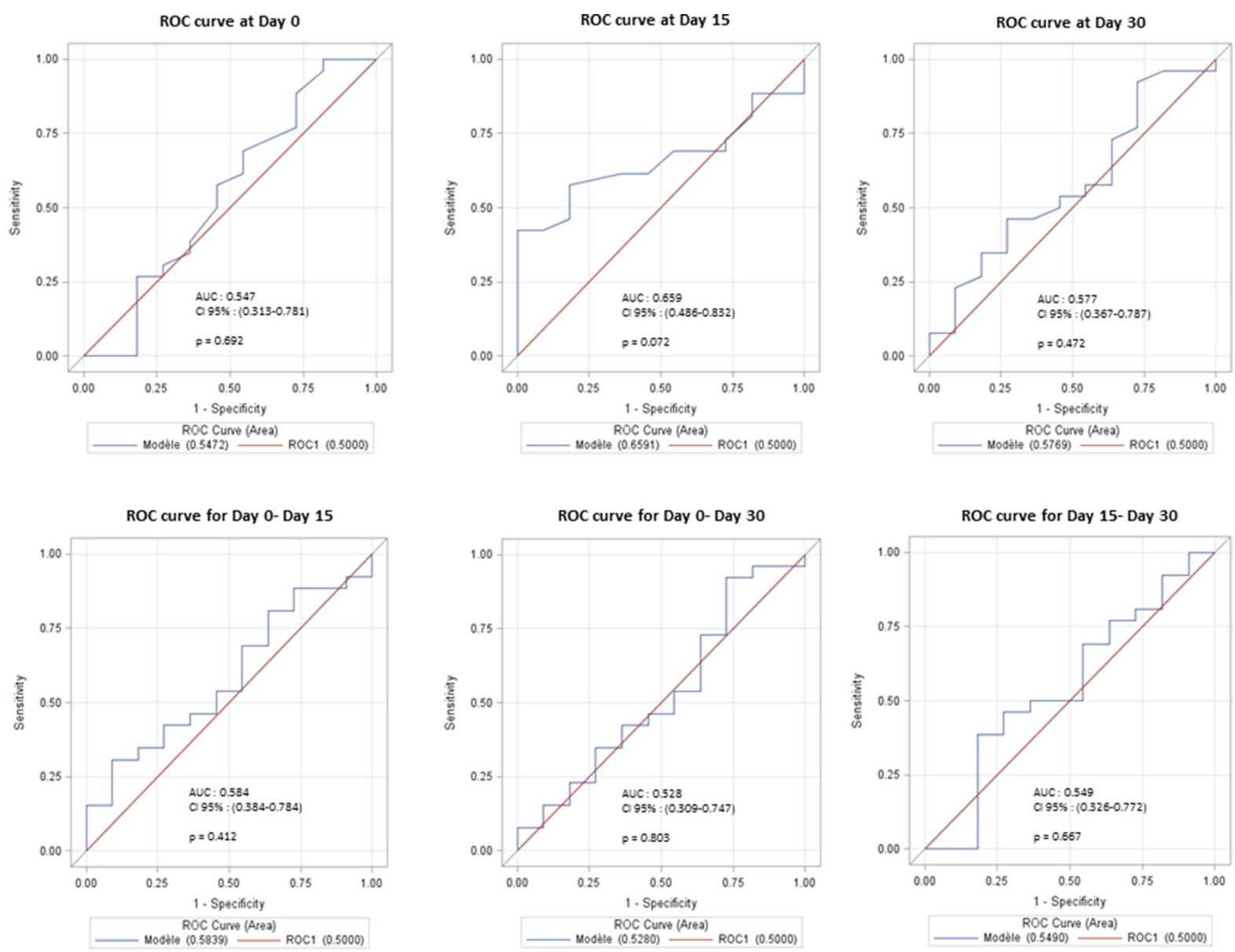

Figure 5: (A) ROC curves modelling the relationship between capillary density at Day 0, Day 15 and Day 30 on response at Day 90. (B) ROC curves modelling the relationship between capillary density variation between Day 0-Day 15, Day 0-Day 30 and Day 15-Day 30 on response at Day 90. 


\section{MATERIALS AND METHODS}

\section{Patients}

Patients with histologically confirmed metastatic colorectal cancer and eligible to receive first-line treatment with bevacizumab combined with chemotherapy were enrolled from May 2013 to July 2015 at the Georges Francois Leclerc Cancer Center in Dijon, France. Written informed consent was obtained for all patients before inclusion (NCT01810744). Bevacizumab was given at $5 \mathrm{mg} / \mathrm{kg}$ every 2 weeks or $7.5 \mathrm{mg} / \mathrm{kg}$ every 3 weeks depending on the chemotherapy regimen. Blood pressure was measured at each visit.

Tumor response was defined according to CHUN criteria [19].

\section{Study design}

In all patients, after inclusion and prior to the initiation of treatment, baseline capillary density was evaluated using capillaroscopy and blood pressure was measured.

An evaluation with a medical consultation, capillaroscopy and blood pressure was carried out during three key visits (Day 15, Day 30 and Day 90).

Tumor response to chemotherapy was evaluated by CT-Scan on day 90 using CHUN criteria. From day 90, data on treatment response, PFS and OS were reported every 3 months until 1 year.

\section{Capillary assessment}

Nail fold capillaries in the dorsal skin of the third finger were visualized by a capillary microscope. Capillary density was defined as the number of erythrocyte-perfused capillaries per $\mathrm{mm}^{2}$. We used a video microscope system Cap-Xview HD (XPort Technologies).

Baseline capillary density corresponded to the number of functional capillaries. Each finger of each hand except the thumb was then observed one by one, around the entire circumference of the lunula. The capillary density was defined as the mean of the eight fingers.

The number of capillaries was counted off-line by an experienced investigator (Nicolas Falvo).

\section{Statistical analysis}

Quantitative variables were described using means and standard deviations or medians and ranges. Relationships between variables and the CHUN response were analyzed using a non-parametric Wilcoxon test. Qualitative variables, excluding missing data, were described using percentages and compared using $\mathrm{Chi}^{2}$ or Fisher tests. Median follow-up was calculated using the reverse Kaplan-Meier method. Survival probabilities were estimated using the Kaplan-Meier method, and the logrank test was used to compare survival curves.
Relative variations in capillary density were calculated as follows: delta D0-D15 = (number of capillaries at D0number at D15)/number at D0. The same formula was applied for delta D0-D30 and D15-D30. The prognostic value of absolute capillary density at D0 and deltas of capillary density were determined using areas under the ROC curves with their $95 \%$ confidence intervals (CI).

Statistical analyses were performed using SAS 9.4 software. All tests were two sided and $P$ values were considered significant when less than 0.05 .

\section{Abbreviations}

CRC: Colorectal cancer; mCRC: metastatic Colorectal cancer; VEGF: Vascular Endothelial Growth Factor; PFS: progression-free survival; OS: overall survival; MAP: Mean arterial blood pressure; D1: day 1; D15: day 15; D30: day 30; ROC: Receiver Operating Characteristic.

\section{Author contributions}

The study was designed by FG and NF. Capillaroscopy was performed by NF. Data were collected by LB, JV, PL and JDF. Statistical analysis was performed by AB. Figures was created by $\mathrm{AB}$ and JDF. The manuscript was written by JDF. All authors have read and validated the manuscript.

\section{ACKNOWLEDGMENTS}

we thank Philip Bastable for his help and its corrections.

\section{CONFLICTS OF INTEREST}

The authors declare no conflicts of interest.

\section{FUNDING}

The authors declare no funding.

\section{REFERENCES}

1. Navarro M, Nicolas A, Ferrandez A, Lanas A. Colorectal cancer population screening programs worldwide in 2016: An update. World J Gastroenterol. 2017; 23:3632. https://doi.org/10.3748/wjg.v23.i20.3632.

2. Van Cutsem E, Cervantes A, Nordlinger B, Arnold D, and ESMO Guidelines Working Group. Metastatic colorectal cancer: ESMO Clinical Practice Guidelines for diagnosis, treatment and follow-up. Ann Oncol. 2014; 25:iii1-iii9. https://doi.org/10.1093/annonc/mdu260.

3. Motzer RJ, Hutson TE, Tomczak P, Michaelson MD, Bukowski RM, Rixe O, Oudard S, Negrier S, Szczylik 
C, Kim ST, Chen I, Bycott PW, Baum CM, Figlin RA. Sunitinib versus interferon alfa in metastatic renal-cell carcinoma. N Engl J Med. 2007; 356:115-124.

4. Miller K, Wang M, Gralow J, Dickler M, Cobleigh M, Perez EA, Shenkier T, Cella D, Davidson NE. Paclitaxel plus bevacizumab versus paclitaxel alone for metastatic breast cancer. N Engl J Med. 2007; 357:2666-2676.

5. Lauro S, Onesti CE, Righini R, Marchetti P. The use of bevacizumab in non-small cell lung cancer: an update. Anticancer Res. 2014; 34:1537-45.

6. Oza AM, Cook AD, Pfisterer J, Embleton A, Ledermann JA, Pujade-Lauraine E, Kristensen G, Carey MS, Beale P, Cervantes A, Park-Simon TW, Rustin G, Joly F, et al. Standard chemotherapy with or without bevacizumab for women with newly diagnosed ovarian cancer (ICON7): overall survival results of a phase 3 randomised trial. Lancet Oncol. 2015; 16:928-936.

7. Saltz LB, Clarke S, Diaz-Rubio E, Scheithauer W, Figer A, Wong R, Koski S, Lichinitser M, Yang TS, Rivera F, Couture F, Sirzen F, Cassidy J. Bevacizumab in Combination With Oxaliplatin-Based Chemotherapy As First-Line Therapy in Metastatic Colorectal Cancer: A Randomized Phase III Study. J Clin Oncol. 2008; 26:20139. https://doi.org/10.1200/JCO.2007.14.9930.

8. Hurwitz H, Fehrenbacher L, Novotny W, Cartwright T, Hainsworth J, Heim W, Berlin J, Baron A, Griffing S, Holmgren E, Ferrara N, Fyfe G, Rogers B, et al. Bevacizumab plus irinotecan, fluorouracil, and leucovorin for metastatic colorectal cancer. N Engl J Med. 2004; 350:2335-2342.

9. Ferrara N, Gerber HP, LeCouter J. The biology of VEGF and its receptors. Nat Med. 2003; 9:669-76. https://doi. org/10.1038/nm0603-669.

10. Escudier B, Bellmunt J, Négrier S, Bajetta E, Melichar B, Bracarda S, Ravaud A, Golding S, Jethwa S, Sneller V. Phase III Trial of Bevacizumab Plus Interferon Alfa-2a in Patients With Metastatic Renal Cell Carcinoma (AVOREN): Final Analysis of Overall Survival. J Clin Oncol. 2010; 28:2144-50. https://doi.org/10.1200/JCO.2009.26.7849.

11. Giantonio BJ, Catalano PJ, Meropol NJ, O’Dwyer PJ, Mitchell EP, Alberts SR, Schwartz MA, Benson AB. Bevacizumab in Combination With Oxaliplatin, Fluorouracil, and Leucovorin (FOLFOX4) for Previously Treated Metastatic Colorectal Cancer: Results From the Eastern Cooperative Oncology Group Study E3200. J Clin Oncol. 2007; 25:1539-44. https:// doi.org/10.1200/JCO.2006.09.6305.

12. Grothey A, Sugrue MM, Purdie DM, Dong W, Sargent D, Hedrick E, Kozloff M. Bevacizumab Beyond First Progression Is Associated With Prolonged Overall Survival in Metastatic Colorectal Cancer: Results From a Large Observational Cohort Study (BRiTE). J Clin Oncol. 2008; 26:5326-34. https://doi.org/10.1200/JCO.2008.16.3212.

13. Heinemann V, von Weikersthal LF, Decker T, Kiani A, Vehling-Kaiser U, Al-Batran SE, Heintges T, Lerchenmüller C, Kahl C, Seipelt G, Kullmann F, Stauch M, Scheithauer
W, et al. FOLFIRI plus cetuximab versus FOLFIRI plus bevacizumab as first-line treatment for patients with metastatic colorectal cancer (FIRE-3): a randomised, openlabel, phase 3 trial. Lancet Oncol. 2014; 15:1065-75. https:// doi.org/10.1016/S1470-2045(14)70330-4.

14. Veronese ML, Mosenkis A, Flaherty KT, Gallagher M, Stevenson JP, Townsend RR, O'Dwyer PJ. Mechanisms of Hypertension Associated With BAY 43-9006. J Clin Oncol. 2006; 24:1363-9. https://doi.org/10.1200/ JCO.2005.02.0503.

15. Henry TD. The VIVA Trial: Vascular Endothelial Growth Factor in Ischemia for Vascular Angiogenesis. Circulation. 2003; 107:1359-65. https://doi.org/10.1161/01. CIR.0000061911.47710.8A.

16. Chojnowski MM, Felis-Giemza A, Olesińska M. Capillaroscopy - a role in modern rheumatology. Reumatologia/Rheumatology. 2016; 2:67-72. https://doi. org/10.5114/reum.2016.60215.

17. Mourad JJ, des Guetz G, Debbabi H, Levy BI. Blood pressure rise following angiogenesis inhibition by bevacizumab. A crucial role for microcirculation. Ann Oncol. 2008; 19:92734. https://doi.org/10.1093/annonc/mdm550.

18. Steeghs N, Rabelink TJ, op 't Roodt J, Batman E, Cluitmans FHM, Weijl NI, de Koning E, Gelderblom H. Reversibility of capillary density after discontinuation of bevacizumab treatment. Ann Oncol. 2010; 21:1100-5. https://doi. org/10.1093/annonc/mdp417.

19. Steeghs N, Gelderblom H, Roodt JO, Christensen O, Rajagopalan P, Hovens M, Putter H, Rabelink TJ, de Koning E. Hypertension and Rarefaction during Treatment with Telatinib, a Small Molecule Angiogenesis Inhibitor. Clin Cancer Res. 2008; 14:3470-6. https://doi.org/10.1158/10780432.CCR-07-5050.

20. Bono P, Elfving H, Utriainen T, Österlund P, Saarto T, Alanko T, Joensuu H. Hypertension and clinical benefit of bevacizumab in the treatment of advanced renal cell carcinoma. Ann Oncol. 2009; 20:393-4. https://doi.org/10.1093/annonc/mdn729.

21. Levy BI. Blood pressure as a potential biomarker of the efficacy angiogenesis inhibitor. Ann Oncol. 2008; 20:200-3. https://doi.org/10.1093/annonc/mdp018.

22. Hayman SR, Leung N, Grande JP, Garovic VD. VEGF Inhibition, Hypertension, and Renal Toxicity. Curr Oncol Rep. 2012; 14:285-94. https://doi.org/10.1007/s11912-012-0242-z.

23. Warschkow R, Sulz MC, Marti L, Tarantino I, Schmied BM, Cerny T, Güller U. Better survival in right-sided versus leftsided stage I - III colon cancer patients. BMC Cancer. 2016; 16:554. https://doi.org/10.1186/s12885-016-2412-0.

24. Chun YS. Association of Computed Tomography Morphologic Criteria With Pathologic Response and Survival in Patients Treated With Bevacizumab for Colorectal Liver Metastases. JAMA. 2009; 302:2338. https://doi.org/10.1001/jama.2009.1755. 